\title{
Brasil e Itália: um breve estudo acerca das causas de menor complexidade
}

\author{
Brazil and Italy: a brief study about the causes \\ of lower complexity
}

Roberta Kelly Silva Souza Comando Militar da Amazônia, CMA, Amazônia - Brasil

Resumo O presente trabalho está voltado ao estudo da solução de conflitos cíveis de menor complexidade no Brasil e na Itália. Justifica-se a temática em estudo em virtude da morosidade processual em solucionar causas simples e de pequeno valor econômico na Justiça comum do Brasil e da Itália. Por intermédio de pesquisa bibliográfica, o presente estudo tem como objetivo geral verificar e analisar como as causas cíveis de menor complexidade são resolvidas no Brasil e na Itália e como objetivo específico demonstrar que o tribunal de pequenas causas proporcionará aos brasileiros e italianos um acesso à Justiça célere e informal, bem como, assegurará os direitos considerados de ínfimo valor econômico. Para tanto, realiza-se um breve recorte sobre a necessidade de procedimentos especiais para as pequenas causas. Após, analisa-se o procedimento adotado no Brasil para a solução de demandas com diminuto valor econômico. Por fim, abordamos o procedimento observado na Itália para as ações de pequeno valor. Por meio de tribunais e procedimentos especiais voltados para as pequenas demandas, o Judiciário torna-se mais próximo daqueles economicamente desfavorecidos, assegurando a todos e indistintamente o tratamento igualitário na resolução dos conflitos.

Palavras-chave: Acesso à Justiça. Causas cíveis. Juizados especiais, MENOR COMPLEXIDADE. 
Abstract The present work is focused on the solution of less complex civil conflicts in Brazil and Italy. The subject under study is justified because of the procedural slowness in solving simple causes and of small economic value in the Common Justice of Brazil and Italy. Through a bibliographical research, the present study has as general objective to verify and analyze how the civil causes of less complexity are solved in Brazil and Italy and as a specific objective to demonstrate that, the small claims court will give Brazilians and Italians access to the Speedy and informal justice, as well, as ensure the rights considered of negligible economic value. To this end, a short cut is made on the need for special procedures for small causes. Afterwards, the procedure adopted in Brazil for the solution of demands with little economic value is analyzed. Finally, we approach the procedure observed in Italy for small value actions. Through special courts and procedures for small claims, the Judiciary becomes closer to those who are economically disadvantaged, ensuring that all are equally treated equally in the resolution of conflicts.

Key-words: Access to Justice. Civil Causes. Special Judges, Less ComPLEXITY.

\section{INTRODUÇÃO}

Desde a mais remota antiguidade o ser humano tem buscado meios para solucionar seus litígios por autoridades responsáveis e órgãos imparciais. Com isso, não é possível afirmar ao certo quando surgiu o primeiro esboço do direito ao acesso à Justiça. Entretanto, é possível notar indícios de seu surgimento no Código de Hamurabi, entre os séculos XXI e XVII a.C.

Com o passar dos anos, houve um maior interesse em torno do acesso ao órgão jurisdicional, principalmente a partir de 1965, quando tornou-se objeto de considerações de processualistas, o que originou três ondas renovatórias do acesso à Justiça. De forma sucinta, a primeira "onda" intentava a assistência judiciária aos menos favorecidos. A segunda "onda" visava a representação dos interesses coletivos. E a terceira "onda" buscava meios para diminuir as barreiras ao acesso à Justiça. 
Entre as novas medidas para transpassar os obstáculos ao acesso jurisdicional surgiram os tribunais de pequenas causas, os quais visam a solução célere dos litígios postos à sua análise e redução dos custos, por intermédio de um procedimento mais simplificado do que aquele adotado no Poder Judiciário comum.

O presente tema justifica-se pelo fato de que, cada vez mais, os cidadãos estão atuantes na procura de seus direitos, buscando o Poder Judiciário quando seus direitos são violados ou ameaçados. Desta feita, destacamos as causas cíveis de menor complexidade, as quais, em virtude de seu ínfimo valor, muitas vezes são desprezadas pelos órgãos jurisdicionais, necessitando assim de um órgão especializado para atendê-las e solucioná-las de maneira célere.

Os tribunais de pequenas causas, conhecidos no Brasil por Juizados Especiais, na Itália o seu correspondente é o Giudice di pace, objetivam proporcionar a solução de controvérsias entre partes de forma simples, rápida e sem custos processuais, reduzindo a litigiosidade das pessoas e impedindo o uso da própria força para resolver conflitos.

Da análise do tema proposto, torna-se imperiosa, então, a seguinte indagação: Como são solucionadas as causas cíveis de menor complexidade no Brasil e na Itália?

Por intermédio de pesquisa bibliográfica acerca do tema abordado, o presente estudo terá, portanto, como objetivo geral verificar e analisar como as causas cíveis de menor complexidade são resolvidas no Brasil e na Itália. Oportunamente, menciona-se que o objetivo específico deste trabalho é demonstrar que o tribunal de pequenas causas proporcionará aos brasileiros e italianos um acesso à Justiça célere e informal, bem como, assegurará os direitos considerados de menor complexidade e ínfimo valor econômico.

O propósito do primeiro capítulo é construir a fundamentação teórica que irá sustentar o presente estudo, tratará a respeito da necessidade de órgãos jurisdicionados possuírem procedimentos especiais para as pequenas causas, pois tais demandas não podem receber o mesmo tratamento procedimental das complexas. Em virtude da necessidade de processamento diferenciado, surgiram os tribunais de pequenas causas em meados de 1970 nos Estados Unidos, Suécia e Inglaterra. 
Depois, no capítulo seguinte, propõe-se o estudo acerca dos Juizados Especiais Cíveis no Brasil, mais especificamente os estaduais, os quais possuem a competência para julgar as causas de menor complexidade que têm o valor de até vinte salários mínimos sem a necessidade de acompanhamento por advogado e de até quarenta salários mínimos acompanhados de advogados. Nessa oportunidade, será apresentado o seu procedimento utilizado para os deslindes das causas postas em sua análise.

Por fim, no último capítulo, por sua vez, trata a respeito do Giudice di pace, o qual é o equivalente aos Juizados Especiais, com suas peculiaridades apresentadas. Portanto, ele é competente na Itália para solucionar as causas com valor de até $€ 5.000,00$ (cinco mil euros), quando a lei não atribuir a competência a outro magistrado, para os casos de indenização por danos causados pela circulação de veículos e barcos, desde que o valor seja de até $€ 20.000,00$ (vinte mil euros) e nos demais casos independentemente do valor elencado no artigo 7 do CPC italiano. Apresentará, ainda, como é realizado o procedimento mediante esse magistrado.

Atualmente, mais do que nunca faz-se necessário o debate acerca do referido tema, pois a população mundial está cada vez mais atuante na busca de seus direitos. Entretanto, esse comportamento faz haver um aumento de demanda processual, tornando ineficaz e morosa a solução das desavenças, dificultando o acesso à Justiça daqueles que possuem causas de ínfimo valor econômico e menor complexidade.

Os tribunais de pequenas causas possuem justamente o objetivo de proporcionar e ampliar ao maior número de jurisdicionados o direito ao acesso à Justiça daquelas demandas mais simples, garantindo a todos esse direito de forma mais célere e eficiente.

\section{A neCESsidade dos PRocedimentos ESPeCiais Para AS PEQUENAS CAUSAS}

O direito ao acesso à Justiça constitui um dos mais importantes temas do direito nos dias atuais. No entanto, não é possível afirmar quan- 
do surgiu, pois desde a antiguidade o ser humano tem se preocupado em garantir a solução dos conflitos existentes por meio da proteção Judicial, assegurando a todos indistintamente o acesso aos órgãos judiciais.

Por sua vez, é possível perceber indícios de seu surgimento, no Código de Hamurabi, entre os séculos XXI e XVII a.C., o qual previa em seu texto a possibilidade do interessado ser ouvido perante aquele que possuía o poder de decisão, demonstrando a visão tradicional do acesso à Justiça, que consiste no acesso ao julgador.

Em 1215, foi assinada a Magna Carta pelo rei Giovanni, senhores feudais e membros do clero na Inglaterra, que previa direitos a todos os membros da cidade de Londres. A partir de então, é possível notar a necessidade de se determinar, de forma clara e eficiente, a atuação e a função do governante, com o intuito de evitar abusos em virtude da posição e autoridade que exercia.

Explica Mattos (2011, p. 29) a respeito da importância da Magna Carta para a época:

[...] entretanto, o que é efetivamente mais relevante é a criação de uma espécie de consciência sobre a existência de uma ordem comum a ser seguida, destinada a ser a representação das castas sociais que compunham a Inglaterra do século XIII [...]. Dessa feita, a efetiva novidade característica do período reside no início de consciência de que a força coativa da qual dispõe o governante não provém de modo natural ou divino, mas surge da comunidade política de maneira integral, mediante a expressa manifestação de vontade em assembleia geral dos cidadãos.

O período moderno teve fortes influências de movimentos revolucionários, como a Revolução Francesa e a Revolução Burguesa, o povo lutava contra o poder exercido pelos reis e os burgueses buscavam limitar os poderes do Estado, surgindo a teoria da separação dos poderes e o princípio da legalidade em uma visão totalmente individualista.

Com o passar dos anos, as ações e os relacionamentos foram perdendo o seu caráter individual que predominava nos séculos XVIII e 
XIX, ocasionando um maior interesse em torno do acesso efetivo à justiça, principalmente no mundo Ocidental, a partir de 1965. A ampliação do acesso à justiça tornou-se objeto de considerações de processualistas, o que originaram as três ondas renovatórias do acesso à Justiça, mais ou menos em sequência cronológica, como explicam Cappelletti e Garth:

\begin{abstract}
Podemos afirmar que a primeira solução para o acesso - a primeira "onda" desse movimento novo - foi a assistência judiciária; a segunda dizia respeito às reformas tendentes a proporcionar representação jurídica para os interesses "difusos, especialmente nas áreas da proteção ambiental e do consumidor; e o terceiro - é o que nos propomos a chamar simplesmente "enfoque de acesso à justiça” porque inclui os posicionamentos anteriores, mas vai muito além deles, representando, dessa forma, uma tentativa de atacar as barreiras do acesso de modo mais articulado e compreensivo (CAPPELLETTI e GARTH, 1988, p. 31).
\end{abstract}

A primeira "onda" do "movimento de acesso à justiça" possuía como objetivo propiciar a assistência judiciária aos menos favorecidos. Desse modo, surgiram os diversos modelos de assistência judiciária, com o intuito de eliminar os obstáculos econômicos, sociais e culturais, permitindo à população maior conhecimento de seus direitos e que se socorressem aos órgãos judiciários para obter efetivamente o seu direito concretizado.

A segunda "onda" trata a respeito da representação dos interesses difusos, ou seja, a representação dos interesses coletivos grupais, uma vez que os direitos pertenciam a grupos de pessoas que possuíam dificuldades de acesso ao Judiciário, em virtude da visão tradicional do processo civil, que previa apenas o processo entre duas partes que se encontrassem em litígio.

Dessa forma, a proteção dos direitos difusos impôs mudanças no direito processual civil, bem como, no papel dos tribunais, ocasionando mudanças na legitimidade para propor a ação, a qual foi ampliada para 
a coletividade. Houve mudanças também nos efeitos da coisa julgada, que passou a abranger grupos e associações interessadas, não mais se restringindo aos litigantes do processo.

A terceira "onda", por sua vez, envolve as mudanças que estão ocorrendo nesses últimos anos, tanto no direito como no Poder Judiciário. Tais mudanças procuram garantir um efetivo acesso à Justiça a todos, buscando vias alternativas e informais para a solução dos litígios, inclusive através da quebra do monopólio estatal da Justiça.

A última onda abrange as anteriores e envolve o conjunto geral de instituições e mecanismos, pessoas e meios procedimentais utilizados para processar e mesmo prevenir litígios. Busca-se diminuir os óbices ao acesso à Justiça e os meios necessários para combater os conflitos da sociedade de forma eficiente.

Com isso, com o intuito de ampliar o acesso à Justiça a todos, surgiu a necessidade da criação de tribunais de pequenas causas ajuizadas por pessoas comuns, as quais possuíam severas limitações na acessibilidade ao Judiciário, em virtude de procedimentos altamente complexos que necessitavam da presença obrigatória de advogados.

Nesse sentido, Cappelletti e Garth (1988, p. 97) defendem:

Há, no entanto, necessidade real de remédios acessíveis e efetivos para pequenas causas, sem grandes (e altamente improváveis) subsídios estatais. [...], sem algum tipo especial de procedimento para as pequenas causas, os direitos das pessoas comuns frequentemente permanecerão simbólicos. $\mathrm{O}$ desafio é criar foros que sejam atraentes para os indivíduos, não apenas do ponto de vista econômico, mas também físico e psicológico, de modo que eles se sintam à vontade e confiantes para utilizá-los, apesar dos recursos de que disponham aqueles a quem eles se opõem. [...]

Desta feita, em virtude da necessidade de criação de tribunais de pequenas causas, muitos países reformularam seus órgãos jurisdicionais e procedimentos com o intuito de ampliar efetivamente o acesso 
à Justiça das causas de menor complexidade, como exemplos temos o sistema dos tribunais de condado para os tribunais de pequenas causas de Nova Iorque de 1972 nos Estados Unidos, o arbitramento de pequenas causas na Inglaterra, em 1973, e o processo de pequenas causas, de 1973, na Suécia (CAPPELLETTI e GARTH, 1988, p. 98-99).

Nessa perspectiva, Cunha (2008, p. 17) destaca:

Os juizados de pequenas causas de Nova York, criados para descongestionar o Poder Judiciário, chamaram a atenção pelo fato de julgar um número expressivo de processos de forma rápida, barata e informal [...] Cada juizado era presidido por um juiz togado, com assistência de diversos árbitros escolhidos entre advogados com ampla experiência profissional. Somente pessoas físicas, maiores de 18 anos de idade, podiam apresentar reclamações nos juizados e as pessoas jurídicas só podiam configurar como réus. A presença de advogado era facultativa, podendo o autor optar entre os juizados ou a corte comum. Neste modelo de juizado de pequenas causas, as decisões por árbitro eram irrecorríveis.

Assim, os tribunais de pequenas causas objetivam promover a redução de custos e duração dos litígios. Os custos, por meio da desoneração da sucumbência, bem como, dos honorários advocatícios, por intermédio da facultatividade da presença de advogados ou até mesmo da proibição de advogados por ambas as partes, para que aquele que possua condições financeiras de arcar com as despesas não obtenha vantagem potencialmente decisiva em face daquele que não tem tais condições. A duração dos litígios, mediante o ajuizamento simples da demanda, formalidades reduzidas ou até mesmo eliminadas, formas mais simplificadas, e funcionários disponíveis para assistir as partes.

Torres (2005, p. 41) assim se manifesta:

O Estado, através de seus poderes, órgãos e as forças vivas das comunidades podem juntos atuar para um novo direito, uma nova visão de acesso à Justiça, vencendo 


\begin{abstract}
barreiras e deficiências existentes do sistema judicial tradicional, lutando por um Poder Judiciário mais democrático e mais participativo na sociedade, junto aos problemas que envolvem seus cidadãos. [...] Com a presença do Judiciário, propicia-se aos cidadãos esclarecerem e encaminharem reclamações sobre seus interesses prejudicados, evitando que diante de dificuldades, renunciem ao exercício do seu direito ou faça uso da força para, pretensamente, garanti-lo. É com um Judiciário atuando em parceria com a comunidade, aproximando os cidadãos, que se propicia o diálogo, estabelecendo uma relação de conhecimento e confiança para dirimir as controvérsias no nascedouro.
\end{abstract}

Diante do formalismo indesejável, a sociedade reivindica meios simplificados e efetivos na solução de litígios. Assim, os tribunais de pequenas causas consistem em um importante mecanismo de democratização do processo, uma vez que tratam as partes paritariamente, sem qualquer privilégio. Com isso, nota-se que cada vez mais esse órgão jurisdicional vem se ampliando ao redor do mundo. Por essa razão, estudaremos como as pequenas causas são examinadas no Brasil e na Itália.

\title{
2. As CAUSAS CÍVEIS de MENOR COMPLEXIDAde NO BRASIL
}

A Constituição Brasileira de 1988, ao reinstalar o Estado Democrático de Direito, ratificou uma maior valorização da Justiça, assim como afirmou a cidadania como delimitadora do poder do Estado. O direito ao acesso à Justiça encontra-se no rol de direitos fundamentais protegidos pela Constituição Brasileira (art. $5^{\circ}$., Inc. XXXV) e possui como objetivo garantir aos cidadãos seus direitos, e não apenas assegurar a propositura da ação, pois, nos dias atuais, a dificuldade não reside mais na ausência de leis garantindo direitos, mas sim como proteger e efetivar tais direitos, para impedir que, apesar das solenes declarações, eles continuem sendo violados.

Com isso, de certa forma a previsão constitucional do direito ao acesso à Justiça estimulou o crescimento de ações judiciais ao longo 
dos anos, desde a sua promulgação. No entanto, o Poder Judiciário não estava aparelhado e apto para receber tantas demandas, o que ocasionou a lentidão na prestação jurisdicional.

Assim, com o intuito de tornar a Justiça célere e informal, a Constituição Brasileira, com base na experiência dos Juizados de Pequenas Causas (Lei no. 7.244/84), criou os Juizados Especiais em seu artigo 98, inciso I, que democratizaram o acesso judicial ao permitirem que as pessoas mais carentes e necessitadas buscassem o Judiciário para solucionarem os seus conflitos.

A Lei 9.099, de 26 de setembro de 1995, foi promulgada para conferir cumprimento ao artigo 98, inciso I, da Constituição Brasileira, dispondo sobre os juizados especiais cíveis e criminais e revogando a Lei 7.244/1984. Entretanto, o inciso I do artigo 98 da Constituição Federal, ao limitar a criação pela União de Juizados Especiais no Distrito Federal, e nos Territórios, prejudicou a instalação do novo sistema no âmbito da Justiça Federal comum e especial, já que em áreas diversas do Distrito Federal e dos Territórios a criação do sistema ficou a critério de cada um dos Estados-Membros, os quais não têm competência legislativa para dispor sobre a Justiça Federal.

A Emenda Constitucional n $n^{\circ} .22$, de 1999, acrescentou o parágrafo único no artigo 98 da Constituição Federal e estabeleceu a competência para a criação dos Juizados Especiais Cíveis e Criminais no âmbito da Justiça Federal. Posteriormente, foi aprovada a Lei $n^{\circ}$. 10.259/01, que dispõe acerca dos Juizados Especiais Cíveis e Criminais Federais. De um modo geral, o processo nos Juizados Especiais Cíveis Federais segue o mesmo modelo adotado nos Juizados Especiais Cíveis Estaduais, sendo seguido o procedimento célere, da mesma maneira como na Lei $n^{\circ} .9 .099 / 95$, evidentemente com as devidas modificações decorrentes da incidência da Lei $n^{\circ}$. 10.259/01.

A Emenda Constitucional n ${ }^{\circ} .45$, de 2004, denominada de "Reforma do Judiciário", renumerou o parágrafo único do artigo 98 da Constituição Federal, passando a prever a criação dos Juizados Especiais no âmbito da Justiça Federal em seu $\S 1^{\circ}$. 
Em 22 de dezembro de 2009, foi instituído um novo juizado pela Lei $n^{\circ}$. 12.153, qual seja, o Juizado Especial da Fazenda Pública, que julga apenas causas contra a Fazenda Pública, e desde que no polo ativo esteja uma pessoa física (capaz ou não), microempresa ou empresa de pequeno porte.

Em que pese existirem diversos Juizados Especiais, este trabalho abordará de forma mais específica a respeito dos Juizados Especiais Cíveis Estaduais, uma vez que são os mais comuns e mais utilizados pela população brasileira, em virtude da maior competência para as demandas. Entretanto, tais causas podem ser ajuizadas na Justiça Estadual Comum, pois a opção da adoção por tais Juizados é facultativa.

Os Juizados Especiais Cíveis Estaduais possibilitam um procedimento fácil, rápido e desburocratizado, buscando a solução de causas simples, onde o valor ou mesmo a menor complexidade da causa desaconselha a procura das vias comuns, permitindo, assim, abrandar o fenômeno da litigiosidade contida dos cidadãos. No entanto, apesar da informalidade que rege esse sistema, o procedimento deve seguir a determinação constitucional do devido processo legal, além das garantias do contraditório e da ampla defesa.

Os Juizados Especiais Cíveis Estaduais são orientados pelos princípios da oralidade, da simplicidade, da informalidade, da economia processual, da celeridade, da conciliação e da transação conforme o previsto no artigo $2^{\circ}$. da Lei $9.099 / 95$, possuindo como objetivo principal oferecer uma maior celeridade e brevidade do processo.

De acordo com Marinoni (2013, p. 86):

A agilização da distribuição da justiça não pode constituir a razão de ser dos Juizados. A filosofia dos Juizados é tocada pelo tema da demora do processo apenas porque o hipossuficiente é aquele que mais sofre com o retardo na entrega da prestação jurisdicional. Assim, é necessário deixar claro, para que não ocorram distorções, que a finalidade dos Juizados não é simplesmente propiciar uma justiça mais célere, mas sim garantir maior e mais efetivo acesso à justiça. 
Os Juizados Especiais Cíveis Estaduais oferecem uma maior proximidade entre a população e o Poder Judiciário, bem como, auxiliam na ampliação do acesso à Justiça e ressaltam a importância da descentralização dos serviços judiciários e da realização de audiências fora da sede da comarca, como estabelece o artigo 94, parágrafo único da Lei 9.099/95.

Com o intuito de atender à população carente, que não pode arcar com as despesas sucumbenciais, a Lei 9.009/95 prevê a possibilidade de participação dos representantes da assistência judiciária e do Ministério Público nas causas que tramitam nos Juizados Especiais Cíveis e Criminais, garantindo, assim, a igualdade de condições entre aquele que dispõe de recursos financeiros para contratar um advogado para defender seus interesses, e aquele que não possui a mesma assistência.

Abreu (2008, p. 216-217) informa sucintamente as regras dos Juizados Estaduais Cíveis:

Nessa perspectiva, dispõe a lei de regência: o pedido deverá ser formulado de maneira simples e em linguagem acessível (artigo 14, $\S 1^{\circ}$.); não se decretará nulidade sem evidência de prejuízo (artigo $13, \S 1^{\circ}$.); citação pelo oficial de justiça independentemente de mandado, inclusive noutra comarca, dispensada a expedição de precatória (artigo 18, inciso III); intimações realizadas por qualquer meio idôneo (artigo 19); provas produzidas em audiência, ainda que não requeridas previamente, comparecendo as testemunhas independentemente de intimação (artigo 34); sentença concisa (artigo 38); julgamento em segunda instância constando apenas de ata, com indicação do processo, fundamentação sucinta e parte dispositiva, servindo como acórdão a súmula do julgamento na hipótese de a sentença ser confirmada por seus próprios fundamentos (artigo 46); início da execução da sentença condenatória postulado de forma oral e sem citação (artigo 52, inciso IV); a alienação de bens penhorados pode ser deferida a pessoa idônea (artigo 52, inciso VII); dispensa de publicação de editais na alienação de coisa de pequeno valor (artigo 52, inciso VIII). 
O Juizado Especial possui duas características que o diferenciam da Justiça Comum, quais sejam, a gratuidade processual em primeira instância e a celeridade visada pelo rito sumaríssimo. Quanto à gratuidade, o sistema permite que pessoas comuns solucionem os conflitos perante um Juiz de Direito, sem a obrigatoriedade de advogado nas causas de até vinte salários mínimos no âmbito estadual, independentemente de contar ou não com os benefícios da Lei 1.060/50, que trata a respeito da assistência judiciária aos necessitados. No entanto, tal gratuidade processual não se repete na fase recursal, uma vez que as despesas processuais existem e a atuação de um advogado é obrigatória, independentemente do valor da causa, como em regra se dá no juízo comum.

Em relação à celeridade, busca-se em todos os momentos pela conciliação e, caso não seja possível, concentra-se na audiência de instrução e julgamento de todos os atos instrutórios, bem como, o acolhimento de provas, permitindo ao juiz proferir sentença na própria audiência.

Nesse sentido, no que tange às provas e à sua complexidade nos Juizados, Chimenti (2012, p. 206) explica:

\footnotetext{
Quando a solução do litígio envolve questões de fato que realmente exijam a realização de intricada prova, após a tentativa de conciliação o processo deve ser extinto e as partes encaminhadas para a Justiça Comum, nos termos do inciso II do art. 51 da Lei n. 9.099/95. É a real complexidade probatória que afasta a competência dos Juizados Especiais dos Estados e do Distrito Federal.
}

Da sentença proferida pelo magistrado, apenas cabe recurso inominado (como regra) com efeito devolutivo (em regra) e, excepcionalmente, é possível a interposição de recurso extraordinário em caso de ofensa à Constituição Federal, sendo possível o uso de agravos e de embargos de declaração.

Em que pese os Juizados Especiais buscarem a celeridade processual, atualmente, consoante dados do CNJ a fase de conhecimento dos Juizados Especiais Estaduais tem durado em média dois anos e três me- 
ses e nos Juizados Especiais Federais, por sua vez, essa fase tem durado cerca de dois anos. A Justiça Estadual Comum tem despendido cerca de dois anos e nove meses na fase de conhecimento. De acordo com tais dados, é possível observar que, após vinte anos de funcionamento dos Juizados, eles atualmente encontram-se abarrotados de processos e despendendo praticamente o mesmo tempo processual que os processos da Justiça Comum.

Os Juizados Especiais, com o intuito de ampliar os meios de acesso ao Poder Judiciário, abarcam demandas que anteriormente não chegavam ao órgão jurisdicional, em virtude, sobretudo, da demora na prestação jurisdicional, que desestimulava a procura pelo órgão judicial de demandas de pequeno valor ou de menor complexidade. Assim, por intermédio dos Juizados é possível resgatar a credibilidade no Judiciário e de propor demandas simples e de baixo valor econômico.

\section{As CAUSAS CÍVEIS DE MENOR COMPLEXIDADE NA ItT́́LIA}

As causas cíveis de menor complexidade e menor valor econômico também recebem especial atenção na jurisdição italiana. Entretanto, na Itália, o sistema adotado para a solução dessas demandas possui algumas diferenças que serão expostas durante este trabalho.

O giudice di pace (juiz de paz) foi instituído pela lei italiana $\mathrm{n}^{\circ}$. 374, de 21 de novembro de 1991, trata-se de um magistrado pertencente ao Judiciário, competente em processos menores de natureza cível e penal, possui os mesmos deveres previstos para os magistrados ordinários, devendo, portanto, exercer as suas funções com imparcialidade, diligência, trabalho duro, honestidade, moderação e equilíbrio. Além disso, mesmo fora do exercício de suas funções, deve evitar qualquer comportamento que comprometa a credibilidade, o prestígio e a dignidade ou o prestígio do Judiciário.

De acordo com a Lei $n^{\circ}$. 374/91, os juízes de paz são nomeados após concurso, devendo ser graduados em Direito, possuindo qualificação para o cargo ou que tenham exercido funções judiciais, bem como, devem ter a idade mínima de 30 anos e máxima de 70 anos, que tenham 
cessado a atividade anteriormente exercida para tomar posse do cargo e, no caso de advogados, que não exerçam a advocacia onde atuarem no cargo de giudice di pace. A nomeação será feita pelo Ministro da Justiça e permanecerá no cargo por quatro anos, esse período poderá ser renovado uma única vez.

Assim como no Brasil, a competência é determinada no momento da propositura da demanda, conforme o disposto no artigo $5^{1}$ do Código de Processo Civil Italiano. No contencioso civil, a competência em razão da matéria e do valor está prevista nos artigos 7 a 17 do Codice di procedura civile italiano. O giudice di pace possui competência para os processos envolvendo bens móveis de valor não superior a $€ 5.000,00$, quando a lei não atribuir tal jurisdição a outro juiz, para os casos de indenização por danos causados pela circulação de veículos e barcos, desde que o valor seja de até $€ 20.000,00$ e nos demais casos independentemente do valor elencado no artigo 7 do CPC italiano, in verbis:

\section{Artigo 7. (1)}

(Competenza del giudice di pace)

Il giudice di pace è competente per le cause relative a beni mobili di valore non superiore euro 5.000,00, quando dalla legge non sono attribuite alla competenza di altro giudice

Il giudice di pace è altresì competente per le cause di risarcimento del danno prodotto dalla circolazione di veicoli e di natanti, purché il valore della controversia non superi euro 20.000,00.

È competente qualunque ne sia il valore:

1) per le cause relative ad apposizione di termini ed osservanza delle distanze stabilite dalla legge, dai regolamenti o dagli usi riguardo al piantamento degli alberi e delle siepi;

Artigo 5. (1)

(Momento determinante della giurisdizione e della competenza)

La giurisdizione e la competenza si determinano con riguardo alla legge vigente e allo stato di fatto esistente al momento della proposizione della domanda, e non hanno rilevanza rispetto ad esse i successivi mutamenti della legge o dello stato medesimo.

(1) Articolo così sostituito dall'art. 2, L. 26 novembre 1990, n. 353. 
2) per le cause relative alla misura ed alle modalità d'uso dei servizi di condominio di case;

3) per le cause relative a rapporti tra proprietari o detentori di immobili adibiti a civile abitazione in materia di immissioni di fumo o di calore, esalazioni, rumori, scuotimenti e simili propagazioni che superino la normale tollerabilità.

O processo inicia-se com a propositura da demanda, que pode ser verbalmente perante o juiz, requerendo-se a convocação para uma audiência, a qual será redigida pelo magistrado com a citação da outra parte para comparecer à audiência, conforme o artigo 316 do CPC italiano. A ação proposta pela parte autora deve conter a indicação do juiz e das partes, a exposição dos fatos e a indicação do objeto. Se o magistrado não ordenar o comparecimento pessoal das partes, estas podem ser representadas por pessoas munidas de mandato escrito, que deve incluir obrigatoriamente $o$ compromisso de conciliação. Tal possibilidade inexiste no Brasil, pois as partes devem obrigatoriamente comparecer pessoalmente.

De acordo com os artigos 316 a 321 do CPC italiano, na primeira audiência o magistrado fará a tentativa de conciliação entre as partes, havendo acordo será elaborada uma ata com os termos do acordo, constituindo um título executivo. Caso não ocorra conciliação entre as partes, em seguida ou em outra data fixada pelo juiz, é realizada outra audiência em que as partes fundamentam a ação, elaboram defesas e exceções, com o intuito de produzir as provas necessárias para o deslinde do feito. Quando o giudice di pace considerar a causa madura para a decisão, convidará as partes para apresentar as suas conclusões e debater a causa.

Barbuto (2015, p. 22) explica o que deve conter a sentença:

L'art. 132 c.p.c. contiene l'elencazione degli elementi essenziali della sentenza, una sorta di "modello legale", ai fini della sua regolarità formale come documento: intestazione; indicazione del giudice che l'ha pronunciata; indicazione delle parti e dei difensori; le conclusioni delle parti; la concisa esposizione dello svolgimento del processo e dei motivi in fatto e in diritto della deci- 
sione (cioè la motivazione); il dispositivo; la data e la sottoscrizione del giudice. Due sono gli elementi formali che assumono rilevanza anche dal punto di vista del contenuto: - la motivazione, ovvero l'esposizione delle ragioni giuridiche e di fatto, una sorta di risposta al "perché" il giudice abbia adottato una certa decisione di accoglimento o di rigetto delle domande e delle eccezioni delle parti; - il dispositivo, cioè la statuizione nel caso concreto, una sorta di comando sintetico (il giudice "condanna", “dichiara", "accerta", “ordina”) sulle singole domande ed eccezioni delle parti. Valgono per il giudice di pace alcune norme di attuazione del c.p.c. dettate per la sentenza del Tribunale.

Assim, diante dos ensinamentos de Barbuto, a sentença deve obedecer a um "Modelo legal" para a sua validade formal contendo, portanto, cabeçalho; indicação do giudice di pace; descrição das partes e dos defensores; as conclusões das partes; a motivação; o dispositivo; a data e a assinatura do juiz. A motivação, nesse caso, é uma espécie de resposta do "motivo" do deferimento ou indeferimento dos pedidos. $\mathrm{O}$ dispositivo diz respeito às questões e as objeções das partes individuais.

A sentença será prolatada pelo mesmo magistrado que realizou o debate entre as partes, salvo nas exceções previstas no artigo 174 do CPC italiano, ${ }^{2}$ que sejam impedimento absoluto ou sérias necessidades do serviço. Com a publicação da sentença, esta só poderá ser revogada ou alterada com a interposição de recursos.

O giudice di pace constitui um modelo de solução de conflitos simplificado, no qual reduz sobremaneira as formalidades presentes nos órgãos judiciais comuns. Por intermédio desse mecanismo, os italianos deslindam suas controvérsias de modo mais simples, rápido e sem custos.

2 Artigo 174.

(Immutabilità del giudice istruttore)

Ilgiudicedesignatoèinvestitodituttal'istruzionedellacausaedellarelazionealcollegio. Soltanto in caso di assoluto impedimento o di gravi esigenze di servizio può essere sostituito con decreto del presidente. La sostituzione può essere disposta, quando è indispensabile, anche per il compimento di singoli atti. 


\section{CONSIDERaÇões FINAIS}

O presente trabalho teve como temática as demandas cíveis de menor complexidade, apresentando como é realizado o procedimento para solver os conflitos entre as partes no Brasil e na Itália. Com o escopo de fundamentar o estudo, tratou-se acerca da necessidade de procedimentos especiais para as pequenas causas, dos Juizados Especiais Cíveis Estaduais no Brasil e do giudice di pace na Itália.

A Constituição Federal Brasileira de 1988 criou os Juizados Especiais em seu artigo 98, inciso I, com base na experiência dos Juizados de Pequenas Causas, os quais surgiram no Brasil com a Lei ${ }^{\circ}$. 7.244/84. Os Juizados Especiais Cíveis Estaduais, que foram estudados neste trabalho, possuem competência para os processos com o valor de até vinte salários mínimos, sem a necessidade de advogado e de até quarenta salários mínimos para aqueles acompanhados de advogados, restringindo, assim, a sua competência para as causas mais simplificadas em razão de seu valor econômico.

O procedimento diante dos Juizados Estaduais visa a conciliação entre as partes, portanto, as partes em qualquer fase do processo podem livremente se conciliarem, submetendo-se aos termos do acordo para o juiz homologar. Entretanto, caso não seja possível a composição na audiência designada para a conciliação, a instrução e o julgamento serão realizados em seguida, toda vez que for possível, caso contrário, será designada outra data. Da sentença proferida, apenas caberá recurso inominado (como regra) com efeito devolutivo (em regra) e, excepcionalmente, é possível a interposição de recurso extraordinário em caso de ofensa à Constituição Federal, sendo admissível o uso de agravos e de embargos de declaração.

O giudice di pace foi criado pela Lei $n^{\circ}$. 374/91 na Itália e possui competência para os processos envolvendo bens móveis de valor não superior a $€ 5.000,00$, quando a lei não atribuir tal jurisdição a outro juiz, para os casos de indenização por danos causados pela circulação de veículos e barcos, desde que o valor seja de até $€ 20.000,00$ e nos demais casos independentemente do valor elencado no artigo 7 do $\mathrm{CPC}$ 
italiano. O processo inicia-se com a propositura da demanda, que pode ser de forma oral perante o juiz, requerendo-se a convocação para uma audiência, que será redigida pelo magistrado com a citação da outra parte para comparecer à audiência. Na data designada para a audiência, é realizada a tentativa de acordo, caso não seja possível será fixada outra data para a realização dos debates. Após essa audiência, será prolatada a sentença, da qual caberão recursos perante o tribunal.

Os Juizados Especiais e o giudice di pace surgem como importantes mecanismos para a democratização do acesso à Justiça dos indivíduos brasileiros e italianos, pois fazem que a prestação jurisdicional torne-se mais próxima daqueles economicamente desfavorecidos, assegurando a todos e indistintamente o tratamento igualitário na resolução dos conflitos, desafogando o Poder Judiciário comum e reduzindo a sua morosidade.

Entretanto, em que pese tais órgãos judiciais atualmente estarem abarrotados de processos, em virtude da grande procura de judicialização dos litígios, continuam sendo modelos de efetividade do acesso à Justiça e de sua efetividade, uma vez que, caso não existissem os indivíduos não poderiam ou se sentiriam constrangidos em ajuizar demandas de pequeno valor, atendendo, dessa forma, à expectativa de um processo justo aos brasileiros e italianos.

\section{REFERÊNCIAS}

ABREU, Pedro Manoel. Acesso à Justiça e Juizados Especiais: o desafio histórico da consolidação de uma justiça cidadã no Brasil. Florianópolis: Conceito Editorial, 2008.

BARBUTO, Mario. Competenze e procedimento civile del giudice di pace.

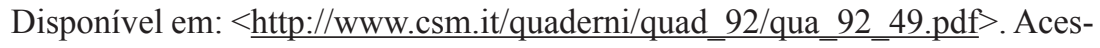
so em: 27 ago. 2015.

BATISTA, Keila Rodrigues. Acesso à Justiça: instrumentos viabilizadores. São Paulo: Letras Jurídicas, 2010. 
BEZERRA, Paulo Cesar Santos. Acesso à Justiça: um problema ético-social no plano da realização do direito, 2. ed. Rio de Janeiro: Renovar, 2008.

BRASIL. Constituição da República Federativa do Brasil: Brasília, DF, 5 out. 1988. Disponível em: <http://www.planalto.gov.br/ccivil_03/constituicao/ constituicao.htm.>. Acesso em: $1^{\circ}$. set. 2015.

BRASIL. Lei ${ }^{\circ}$. 9.099, de 26 de setembro de 1995. Dispõe sobre os Juizados Especiais Cíveis e Criminais e dá outras providências. Brasília, DF, 26 set. 1995. Disponível em: http://www.planalto.gov.br/ccivil_03/LEIS/L9099.htm. Acesso em: $1^{\circ}$. set. 2015.

CAPPELLETTI, Mauro; GARTH, Bryant. Acesso à Justiça. Tradução de Ellen Gracie Northfleet. Porto Alegre: Sergio Antonio Frabis Editor, 1988.

CICHOCKI NETO, José. Limitações ao Acesso à Justiça. Curitiba: Juruá, 2009.

CHIMENTI, Ricardo Cunha. Teoria e prática dos Juizados Especiais Cíveis Estaduais e Federais, 13. ed. São Paulo: Saraiva, 2012.

CONSELHO NACIONAL DE JUSTIÇA. Justiça em números. Disponível em: <http://www.cnj.jus.br/files/conteudo/arquivo/2017/05/4c12ea9e44c05e1 f766230c0115d3e14.pdf>. Acesso em 21 jun. 2017.

CUNHA, Luciana Gross. Juizado Especial: criação, instalação, funcionamento e a democratização do acesso à justiça. São Paulo: Saraiva, 2008.

GRINOVER, Ada Pellegrini. O Processo em Evolução, 2. ed. Rio de Janeiro: Forense Universitário, 1998.

ITALIA. Codice di procedura civile. Disponível em: http://www.altalex.com/ documents/codici-altalex/2015/01/02/codice-di-procedura-civile. Acesso em: $1^{\circ}$. set. 2015.

ITALIA. Legge n. 374/ 1991. Disponível em: http://www.padovanet.it/giudice/legge\%20n.374.htm. Acesso em: $1^{\circ}$. set. 2015.

ITALIA. Giudice de pace (ordenamento italiano) Disponível em: https:// it.wikipedia.org/wiki/Giudice_di_pace_(ordinamento_italiano). Acesso em 18 set. 2015.

MANCUSO, Rodolfo de Camargo. Acesso à Justiça: condicionantes legítimas e ilegítimas. São Paulo: Revista dos Tribunais, 2011. 
MARINONI, Luiz Guilherme. Técnica Processual e Tutela dos Direitos, 4. ed. São Paulo: Revista dos Tribunais, 2013.

MATTOS, Fernando Pagani. Acesso à Justiça: um princípio em busca de efetivação. Curitiba: Juruá, 2011.

RODRIGUES, Horácio Wanderlei. Acesso à Justiça no Direito Processual Brasileiro. São Paulo: Acadêmica, 1994.

TORRES, Jasson Ayres. Acesso à Justiça e Soluções Alternativas. Porto Alegre: Livraria do Advogado, 2005.

\section{Sobre a autora}

\section{Roberta Kelly Silva Souza}

Mestra em Direito Constitucional pela Instituição Toledo de Ensino. Pós-Graduada em Giustizia Costituzionale e Tutela Giurisdizionale pela Universitá di Pisa, UNIPI, Itália. Especialista em Direito Público e Direito Processual pelo Centro Universitário de Ensino Superior do Amazonas. Bacharel em Direito pela Universidade Nilton Lins. Assessora Jurídica do Comando Militar da Amazônia.rkellyss@yahoo.com.br

Submetido em: 28-11-2016

Aceito em: 6-6-2017 